ECCOMAS

Proceedia $6^{\text {th }}$ ECCOMAS Thematic Conference on Computational Methods in Structural Dynamics and Earthquake Engineering

M. Papadrakakis, M. Fragiadakis (eds.) Rhodes Island, Greece, 15-17 June 2017

\title{
EXPERIMENTAL AND NUMERICAL RESPONSE OF CFRP- STRENGTHENED CONCRETE BEAMS WITH LOW OR MEDIUM STEEL CORROSION
}

\author{
Garyfalia G. Triantafyllou ${ }^{1}$, Theodoros C. Rousakis ${ }^{2}$, and Athanasios I. Karabinis ${ }^{3}$ \\ ${ }^{1} \mathrm{PhD}$ Student \\ Laboratory of Reinforced Concrete, Democritus University of Thrace (DUTh) \\ gtriant@civil.duth.gr \\ ${ }^{2}$ Assistant Professor \\ Laboratory of Reinforced Concrete, Democritus University of Thrace (DUTh) \\ trousak@civil.duth.gr \\ ${ }^{3}$ Professor \\ Laboratory of Reinforced Concrete, Democritus University of Thrace (DUTh) \\ karabin@civil.duth.gr
}

Keywords: Reinforced Concrete Beams, Corrosion, Repair, Carbon Fiber Reinforced Polymer CFRP, Finite Element Modeling (FEM).

\begin{abstract}
The present study deals with the validation of a numerical model that can approximate the flexural behavior of corroded reinforced concrete beams patch repaired and strengthened with carbon fiber reinforced polymer (CFRP). Six reinforced concrete beams were corroded under an accelerated corrosion technique to low and medium corrosion levels respectively. Two beams were used as control, while the remaining four were patch repaired and strengthened with externally bonded reinforcement (EBR) and near surface mounted reinforcement (NSM) with equivalent axial rigidity. After repairing the concrete substrate and subsequent bonding of the CFRP reinforcement, the beams were tested to failure under fourpoint loading. The developed $3 D$ finite element models take into account the different mechanical properties and detailing of corroded bars and of the mortar patch as well as of the existing concrete - mortar patch interface and of the NSM or EBR FRP - mortar patch interface. The FE analyses may reproduce the observed modes of failure including crushing of the concrete after steel yielding and debonding of CFRP. The analytical load-deflection curves compare well with the experimental flexural behavior of the corroded RC beams patch repaired and strengthened with EBR and NSM CFRP laminates.
\end{abstract}




\section{INTRODUCTION}

A lot of research has been conducted to assess damaged reinforced concrete structures affected by corrosion of steel reinforcement. The damage is caused by the reduction of crosssectional area of the steel and reduction of its strain at failure and bond to concrete as well as concrete cracking in the RC elements and leads to early failure of structures [1-3]. Externally bonded carbon fiber reinforced polymer (CFRP) reinforcements (EBR) constitute effective structural strengthening solutions for existing RC structures. However, the maximum FRP tensile stress that can be utilized according to this technique is limited by the bond performance between FRP systems and concrete substrate. Near surface mounted (NSM) technique is also used for strengthening deteriorated structures, where thin laminates or bars are installed into slits opened in the concrete cover. The NSM strengthened members can be more ductile than EBR strengthened members and fail at much higher FRP strains [4,5]. Not much information is available on steel corroded and FRP repaired RC beams, especially on the efficiency of FRP strengthening applied on repaired substrate.

Although an extensive experimental research has been conducted on the application of FRP systems for the flexural strengthening of $\mathrm{RC}$ elements, numerical analyses are of a great importance to evaluate the influence of the crucial design parameters on the strengthening efficiency. Numerical investigations of FRP strengthened RC members, focused on EBR technique, have been conducted in parallel to the experimental work. Many researchers simulated the behavior of RC members strengthened in flexure with externally bonded FRPs assuming perfect bond between concrete-epoxy and epoxy-FRP interface [6,7]. A few researchers considered the debonding effects in FE modeling of EBR strengthened RC beam [8-10]. The behavior of NSM CFRP strengthened structures using 2D or 3D numerical models have been investigated by [11] assuming perfect bond conditions (no slip). In this case the FRP debonding failure cannot be predicted. Finite element modeling of NSM CFRP strengthened members considering debonding is very limited [12,13]. The development of a FE model of RC members strengthened with FRP materials considering the nonlinear behavior of constituent materials and FRP-epoxy-concrete interfaces is required to reproduce the failure mechanisms of strengthened members.

The cohesive zone model approach is one of the most commonly used tools to investigate interfacial debonding. This approach assumes that a cohesive damage zone or softening plasticity develops near the crack tip. Camata et al. [14] investigated the bond failure mechanism of FRP laminates glued to concrete and found that the nonlinear fracture mechanics model follows very closely the experimentally observed cracking sequence. Pham et al. [15] used nonlinear fracture mechanics to study bond between CFRP and concrete and showed that the interface crack model can represent successfully bond behavior. Arduini et al. [16] presented a FE study of end cover separation in FRP-strengthened RC beams in which a perfect bond was assumed between FRP and concrete as well as between steel and concrete, where a good agreement was observed between the predicted and experimental loaddeflection curves. Yang et al. [17] used a discrete crack model based on linear elastic fracture mechanics for the concrete and the bond-slip behavior between steel and concrete in order to simulate the failure of strengthened beams. Their model required a re-meshing process which is time consuming. Neale et al. [18] presented nonlinear finite element modeling of RC members externally strengthened with FRPs and shown that with appropriate constitutive models for the FRP/concrete interfaces, the numerical predictions agree well with the experimental measurements in terms of load-deflection relationships and failure modes. Almassri et al. [19] used FE models of corroded RC beams strengthened with a NSM CFRP rod assuming full bond between FRP and concrete and could capture well the load capacity 
and the failure modes. A 3D FE model was used by Rezazadeh et al. [20] to simulate strengthened beams with CFRP profiles, which was capable of simulating the nonlinear behavior of the materials and both interfaces between concrete-epoxy and epoxy-CFRP. The ultimate shear capacity and the experimental modes of failure including diagonal concrete cracking and debonding of the FRP strips could be predicted well by the numerical simulation of Manos et al [21].

The present study investigates experimentally and analytically the flexural behavior of corroded RC beams patch repaired and strengthened with CFRP laminates with EBR and NSM techniques. 3D models have been developed in ABAQUS to investigate the specific mode of failure of non-strengthened and strengthened beams. The numerical analyses could predict with satisfactory accuracy the experimental load-deflection behavior, the ultimate capacity of the beams as well as the observed failure modes including debonding of CFRP laminate and debonding at the epoxy-CFRP NSM strips interface.

\section{EXPERIMENTAL INVESTIGATION}

\subsection{Beam tests}

A total of $7 \mathrm{RC}$ beams with a width of $150 \mathrm{~mm}$, a height of $300 \mathrm{~mm}$ and a length of 2300 $\mathrm{mm}$ were tested in the Reinforced Concrete Laboratory of D.U.Th. Beam RC-N was a reference beam with no corrosion, while the remaining six beams were subjected to an accelerated corrosion technique at low and medium corrosion levels. Beam RC-COR1 was the control corroded beam at low corrosion level, while RC-COR1S1 and RC-COR1S2 were corroded beams repaired and strengthened with EBR and NSM carbon FRP systems respectively. At medium corrosion level the control beam was named RC-COR2, while the repaired and strengthened with EBR and NSM CFRP was named RC-COR2S1 and RCCOR2S2 respectively. All beams had three tensile ribbed rebars of $12 \mathrm{~mm}$ diameter, two 10 $\mathrm{mm}$ diameter ribbed bars in compression, stirrups of $8 \mathrm{~mm}$ diameter spaced at $150 \mathrm{~mm}$ (with $50 \mathrm{~mm}$ spacing at the support) and $20 \mathrm{~mm}$ clear concrete cover. The typical geometry and reinforcement of beams are shown in figure 1.

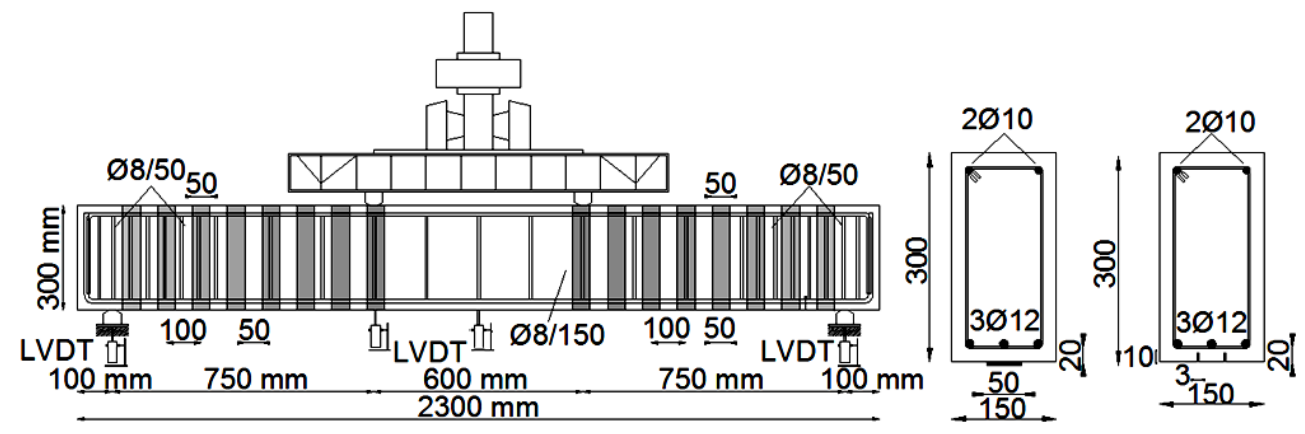

Figure 1: Beam geometry and reinforcement details of test specimens.

\subsection{Materials}

The average maximum compression stress on cylindrical concrete specimens was 34.6 $\mathrm{MPa}$, the elastic modulus $32300 \mathrm{MPa}$ and the tensile strength was $2.2 \mathrm{MPa}$ after 28 days. The tensile strength, measured using the splitting test, was $2.2 \mathrm{MPa}$. Tensile tests on steel were 
also executed and the yield strength was measured equal to $552.2 \mathrm{MPa}$, while the ultimate strength $652.5 \mathrm{MPa}$.

After removal of cracked concrete, corroded rebars were treated with corrosion inhibitor for reinforced concrete and an epoxy-cement and anti-corrosive bonding primer. Substrate repair was realized with polymer modified cementitious repair mortar having compressive strength of $50 \mathrm{MPa}$ at 28 days. Table 1 shows the mechanical characteristics of CFRP laminate, CFRP NSM plates and U-CFRP sheets for shear strengthening. Epoxy resin was used for the bonding of CFRP laminate having flexural strength of $90 \mathrm{MPa}$, tensile strength of $30 \mathrm{MPa}$ and elastic modulus of $11200 \mathrm{MPa}$. The epoxy resin for the bonding of CFRP plates into slits, filling the grooves in NSM technique and for UCFRP sheets had tensile strength of $30 \mathrm{MPa}$ and elastic modulus of $4500 \mathrm{MPa}$.

\begin{tabular}{lccccc}
\hline Material & $\begin{array}{c}\text { Width } \\
(\mathrm{mm})\end{array}$ & $\begin{array}{c}\text { Thickness } \\
(\mathrm{mm})\end{array}$ & $\begin{array}{c}\text { Young's } \\
\text { Modulus } \\
(\mathrm{GPa})\end{array}$ & $\begin{array}{c}\text { Ultimate } \\
\text { stress } \\
(\mathrm{MPa})\end{array}$ & $\begin{array}{c}\text { Ultimate } \\
\text { strain } \\
(\%)\end{array}$ \\
\hline CFRP laminate & 50 & 1.2 & 165 & 3100 & 17 \\
CFRP NSM plates & 10 & 3 & 165 & 3100 & 17 \\
U-CFRP sheets & 50 & 0.167 & 230 & 4000 & 17 \\
\hline
\end{tabular}

Table 1: Characteristics of CFRP materials.

\subsection{Accelerated Corrosion Process}

The accelerated corrosion process included beams placed inside a tank which contained industrial salt solution $\mathrm{NaCl}$ of $3 \%$ concentration and then subjected to wet-dry cycles for better physical representation of the natural corrosion process (total of 8 weeks for low corrosion level and 16 weeks for medium corrosion level). The beams were also subjected to constant electric current. The current was only applied during the wetting period. Corroded tensile rebars were extracted from beams after testing, were cleaned of rust and weighed according to ASTM-G1 90 standard [22]. The gravimetric mass loss for low corrosion level was measured equal to $\mathrm{m}_{\text {grav,low }}=7.56 \%$, while for medium corrosion level $\mathrm{m}_{\text {grav, med }}=15.48 \%$.

\subsection{Repair Technique}

The damaged concrete cover was removed to the level of the tensile steel reinforcement along the whole length of the beams. The exposed corroded steel bars were cleaned and corrosion products were removed by mechanical means. Corrosion inhibitor was applied with a brush and then an epoxy-cementitious bond agent layer to the repair zones. Finally, the polymer modified cementitious mortar was applied by patching technique to form $20 \mathrm{~mm}$ cover.

Beams RC-COR1S1 and RC-COR2S1 were strengthened in flexure with CFRP laminate on the tensile bottom. Beams RC-COR1S2 and RC-COR2S2 received two CFRP NSM plates inserted into the mortar cover grooves at the tension side, having equal axial rigidity with EBR FRP laminate. In order to prevent shear failure, each shear span was strengthened with eight U-shaped CFRP strips of $50 \mathrm{~mm}$ width and in two layers spaced at $50 \mathrm{~mm}$ (figure 1). 


\subsection{Summary of the observed behavior and modes of failure}

Detailed mapping of corrosion-induced crack patterns and of their widths were also recorded at the end of each corrosion cycle. A main longitudinal crack was formed at the tensile bottom of each corroded beam, running parallel to the middle tensile rebar and on the front and back sides. These cracks increased their width as corrosion came along and at the end of the last corrosion cycle the maximum width of the bottom face was measured equal to $0.35 \mathrm{~mm}$ for low corrosion level and equal to approximately $0.90 \mathrm{~mm}$ for medium corrosion level.

All specimens were subjected to four- point monotonic loading up to failure. The load was applied using a $500 \mathrm{kN}$ actuator through a spreader steel beam to the specimen (Figure 1).

The failure mode for non corroded RC-N and corroded RC-COR1 beams was flexural by yielding of tensile steel bars, followed by crashing of concrete at the compression zone. Corroded beam RC-COR2 had the two external corroded tensile bars fractured before concrete crushing. The yield load of beam RC-COR 1 was about 5.55\% lower than that of the uncorroded beam RC-N and of beam RC-COR2 was about $20.58 \%$ lower than RC-N and $16.17 \%$ lower than RC-COR1. The maximum bearing load of RC-COR1 was around $4 \%$ lower than reference beam RC-N and of beam RC-COR2 was about $14.58 \%$ lower than RC-N and $11.15 \%$ lower than RC-COR1. A slight increase in the deflection capacity of $2.45 \%$ for the corroded beam RC-COR1 and a decrease of $15.47 \%$ for RC-COR2 were recorded compared to non-corroded RC-N. The load-midspan deflection curves of beams at low and medium corrosion level are shown in figure 2(a) and 2(b) respectively.

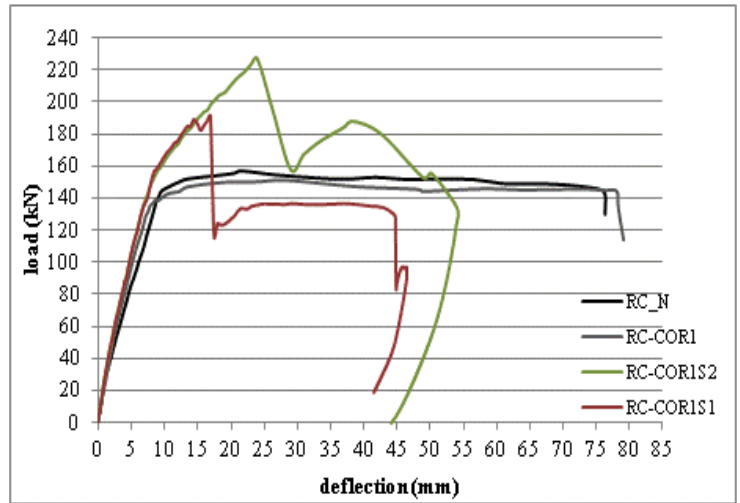

(a)

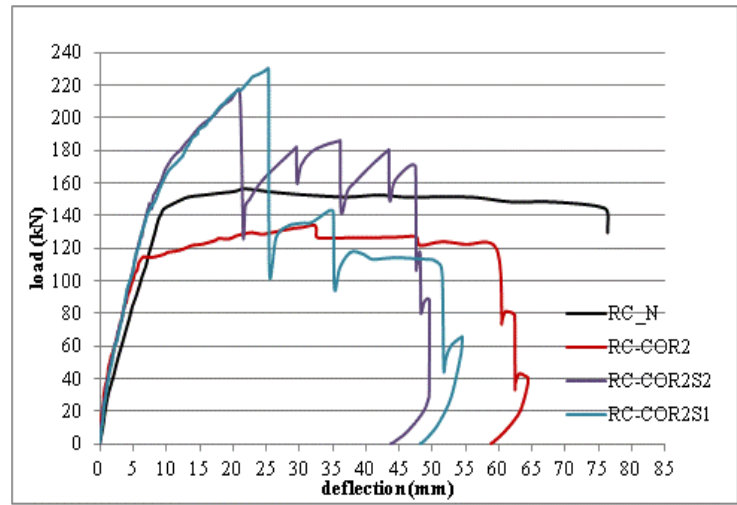

(b)

Figure 2: Load-deflection curves of tested beams.

For patch repaired and strengthened corroded beams at low corrosion level RC-COR1S1 and RC-COR1S2, the failure mode was debonding of the flexural CFRP laminate for the first and debonding at the epoxy-CFRP strips interface and localized splitting of the epoxy cover for the second, after yielding of the tensile steel reinforcement. Then, intermediate debonding between the old concrete and repaired mortar layer followed and finally the compressive concrete zone crushed. The yield load of RC-COR1S1 was $8.4 \%$ higher than the non corroded $\mathrm{RC}-\mathrm{N}$ and $14.4 \%$ more than the corroded unstrengthened beam RC-COR 1 . The maximum load was $22.1 \%$ higher than that of RC-N and $27.1 \%$ than RC-COR1 at $17 \mathrm{~mm}$ deflection. RC-COR1S2 beam yielded at a load 6.2\% higher than RC-N and 12\% higher compared to RC-COR1. The ultimate load at debonding of the NSM strengthened beam was $18.2 \%$ higher compared to the EBR strengthened beam, 44.4\% higher than RC-N and 50.2\% higher than RC-COR1 at $24.1 \mathrm{~mm}$ deflection. 
For patch repaired and strengthened corroded beams at medium corrosion level RCCOR2S1 and RC-COR21S2, the failure mode was debonding of the flexural CFRP laminate for the first and debonding in the form of concrete cover separation for the second, after yielding of the tensile steel reinforcement. At excessive deflections rupture of two of the corroded tensile bars occurred before concrete crushing. Intermediate debonding between the old concrete and repaired mortar layer was also noticed. The yield load of RC-COR2S1 was $3.3 \%$ higher than the non corroded $\mathrm{RC}-\mathrm{N}$ and $30.1 \%$ more than the corroded unstrengthened beam RC-COR2. The maximum load of RC-COR2S1 was $46.8 \%$ higher than that of RC-N and $71.9 \%$ than that of RC-COR2 at $25.3 \mathrm{~mm}$ deflection. RC-COR2S2 beam yielded at a load $3.9 \%$ higher compared to RC-N and 30.9\% higher compared to RC-COR2. The ultimate load at debonding of NSM strengthened beam was $6.1 \%$ lower compared to the EBR strengthened beam, 37.8\% higher than RC-N and 61.3\% higher than RC-COR2 at $21.03 \mathrm{~mm}$ deflection. Despite the higher mass loss of beams at medium corrosion level, the CFRP laminate developed higher strain at debonding, resulting in higher maximum bearing load of the beam. Figure 3 shows corroded beams at medium corrosion level, patch repaired and strengthened with CFRP materials after failure.

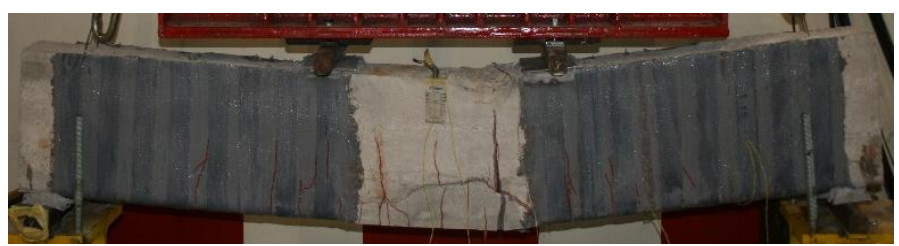

(a)

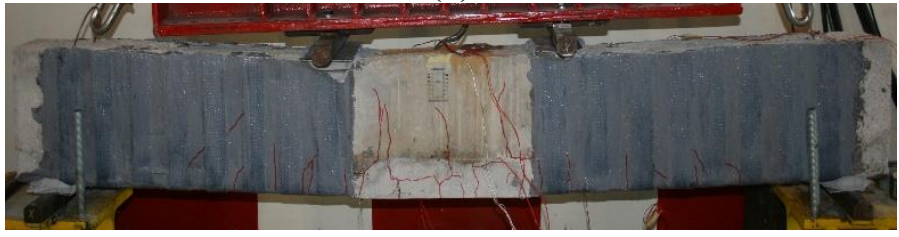

(b)

Figure 3: Beam RC-COR2S1 (a) and beam RC-COR2S2 (b) after failure.

\section{NUMERICAL ANALYSIS}

\subsection{Modeling assumptions}

This paper utilizes a 3D finite element (FE) approach that takes into account the nonlinear behavior of the used materials and the CFRP-epoxy adhesive and concrete-epoxy adhesive interfaces capacity using software ABAQUS [23]. The models adopt eight-node 3D solid elements for concrete, patch repair substrate, the interface between these two concretes and epoxy adhesive. The CFRP NSM strips, laminates and U-CFRP sheets were idealized as linear 4-noded shell elements and were tied to their respective elements. The longitudinal reinforcing bars and the steel stirrups were discretized with linear two-node truss elements embedded in the concrete region. A refined mesh was applied on the whole model with a mesh size of $25 \mathrm{~mm}$. The loading and support conditions were simulated according to the characteristics of the experimental setup and the load was applied using displacement control. The nonlinear analysis has been conducted using the explicit dynamics solver ABAQUS/EXPLICIT. Figure 4 shows the skeleton and mesh of the FE models. 

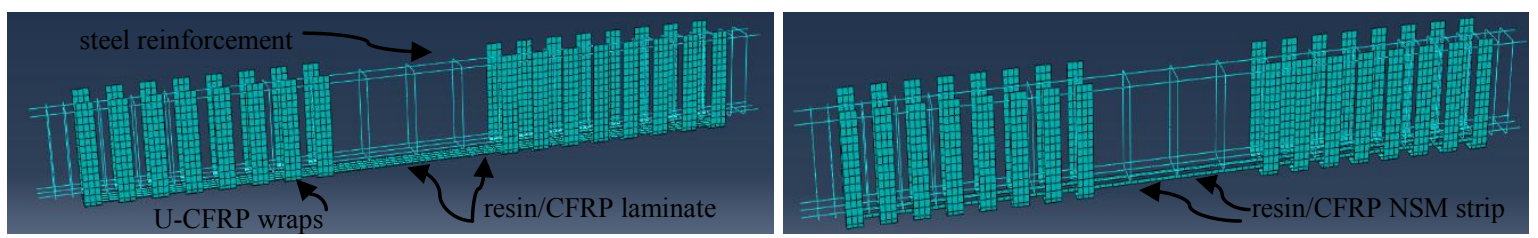

Figure 4: Skeleton and mesh of the FRP U-wraps of the FE Models.

\subsection{Material modeling}

Concrete Damage Plasticity (CDP) model was adopted to simulate the concrete's nonlinear behavior that is linear isotropic elasticity in combination with isotropic tensile and compressive plasticity. The CDP model considers two main damage mechanisms of the concrete: cracking formation and propagation in tension and elasto-plasticity in compression. The essential parameters of the CDP model (dilation angle $\psi$, plastic potential eccentricity e, stress ratio $\mathrm{f}_{\mathrm{bo}} / \mathrm{f}_{\mathrm{co}}$ the ratio between the compressive strength in bi- and uni-compression stress $f_{b o}$ and $f_{c o}$ respectively, shape of the loading surface $K_{c}$ and viscosity parameter $V$ ) were estimated based on the recommended range of values given by ABAQUS manual [23] and Kmiecik and Kaminski [24]. A post failure stress-strain relationship for concrete subjected to tension which accounts for tension stiffening strain softening and reinforcement interaction with concrete was used. The uniaxial behavior of the uncracked concrete in tension was assumed to be linear up to the concrete tensile strength $\sigma_{\mathrm{to}}=\mathrm{f}_{\mathrm{ct}}$. Under uniaxial compression the response is linear until the $\sigma_{\mathrm{co}}=0.40 \mathrm{f}_{\mathrm{cc}}$ of the concrete compressive strength and the concrete nonlinear stress-strain relationship was obtained according to recommendations of EN 1992-1-1[25] using stresses, inelastic strain and damage properties. In the plastic regime the response is characterized by stress hardening followed by strain softening beyond the ultimate stress $\sigma_{\mathrm{cu}}=\mathrm{f}_{\mathrm{cc}}$. Poisson's ratio was assumed equal to 0.2 .

An elasto-plastic model was adopted for the truss elements to simulate the behavior of the steel reinforcement. The elasto-plastic curves were specified from tensile tests, whilst Poisson's ratio was assumed equal to 0.3. The tensile behavior of the CFRP reinforcement was assumed linear elastic up to the ultimate tensile strength.

The adhesive epoxy resin layer was modeled as a cohesive zone endowed with a tractionseparation response to reproduce the debonding of the CFRP strip from the concrete. A mixed mode of debonding comprising stress-separation and shear stress-slip was used to simulate the concrete-epoxy resin interface, as well as the interface between the old and repaired concrete, while the shear stress slip was used to simulate the CFRP-epoxy resin interface Damage evaluation was defined in terms of fracture energy with linear softening. The normal tensile stress and tensile fracture energy of the concrete-epoxy interface was limited to the tensile strength and fracture energy of the concrete and the maximum shear stress and shear fracture energy was adopted from the model by [26]. The maximum shear stress of CFRP -epoxy resin interface and the shear fracture energy was estimated by the area under the proposed shear stress-slip curve [27]. The initial elastic stiffness for all three modes of debonding was set according to Turon et al. [28].

\subsection{Results of Finite Element Analysis}

To assess the predictive performance of the described numerical model, the obtained load versus mid-span deflection response was compared with the experimentally recorded ones. For the non corroded beam RC-N, a slight increase of $1 \%$ in the yielding load and a decrease 
of $5.1 \%$ in the ultimate load were recorded for the FE model with respect to the experimental one, while the analysis was terminated at $80 \mathrm{~mm}$ deflection at concrete crushing. For the corroded beams, the steel mass loss measured experimentally and the stress-strain values for steel were adopted from the tensile tests of non corroded steel coupons. For corroded beam RC-COR 1 the analytical yield load was $1 \%$ lower than the experimental one, while the ultimate load was 7.2\% lower. Corroded beam RC-COR2 presented yield load almost equal and ultimate load around 10\% lower than the corresponding experimental values. The analytical ultimate deflection for both beams is in good agreement with experiments. Flexural failure mode was also observed in FE models by yielding of the tensile reinforcement followed by crushing of the concrete in compression zone.

The failure modes of corroded strengthened beams at the maximum load carrying capacity were numerically predicted in accordance with the experimental. Figure 5 indicates a good predictive performance with small deviations with respect to the maximum load and its corresponding deflection. The analytical ultimate load for strengthened beam at low corrosion level RC-COR1S1 was $1.5 \%$ lower, while for beam RC-COR1S2 was $2.9 \%$ higher that the experimental ones. For beam RC-COR2S2 at medium corrosion level with NSM strengthening, the analytical ultimate load was at approximately $5 \%$ higher than the experimental one. The prevailing failure mode of the beam at maximum load was predicted well by the analysis (debonding at the epoxy-CFRP strips interface). For strengthened beam RC-COR2S1 at medium corrosion level, the analytical ultimate load was quite lower than the experimental. In fact, the experiments suggest that the CFRP laminate developed much higher tensile strain prior to debonding, attributed to the anchoring through U-CFRP wraps (placed for shear strengthening). Thus, in order to predict the experimental behavior of beam RCCOR2S1, a much higher strength at the interface between the old and the patch-repaired mortar and the epoxy-resin material should be considered. Further experimental and analytical investigation should be conducted in this field.

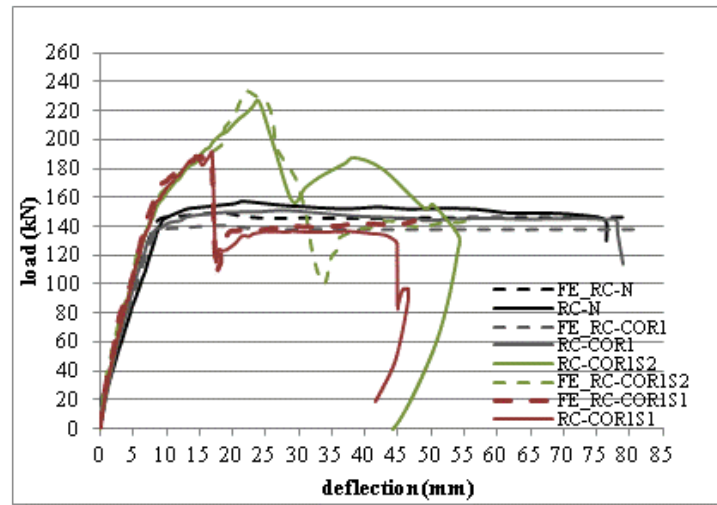

(a)

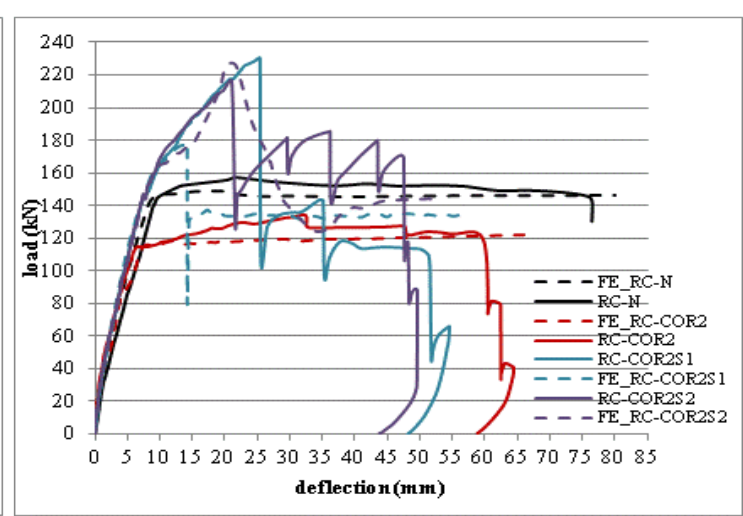

(b)

Figure 5:Experimental vs FE model load-deflection curves of tested beams.

\section{CONCLUSIONS}

This study investigated the structural performance of beams with corroded steel bars at low or medium level, after their patch repair and CFRP-EBR or NSM strengthening. All repaired beams presented increased load carrying capacity with respect to the non corroded beam, even at medium corrosion level for the tensile reinforcement. Both EBR and NSM techniques may repair efficiently RC structures with corroded steel bars provided that the damaged concrete 
cover is replaced with suitable mortar patch. Developed 3D FE models were used to reproduce the experimental performance. For non-corroded beam and for reference corroded beams the P-d results and the flexural failure mode by yielding of the tensile reinforcement followed by crushing of the concrete in compression zone were captured well from the FE models. The good performance of the numerical analysis is also demonstrated by comparing the experimentally and analytically predicted ultimate flexural capacity for all strengthened corroded beams. The prevailing failure modes of debonding of CFRP laminate and debonding at the epoxy-CFRP strips interface of the beams at maximum load were predicted well by the analysis in most of the cases.

\section{ACKNOWLEDGEMENTS}

This research was supported by the IKY (Greek State Scholarships Foundation) RESEARCH PROJECTS FOR EXCELLENCE IKY/SIEMENS. The authors wish to acknowledge the support by Sika Hellas for providing the CFRP reinforcement, filling materials (adhesive epoxy), materials for corrosion protection and mortar for the repair technique.

\section{REFERENCES}

[1] G. Al-Sulaimani, M. Kaleemullah, I. Basunbul, Rasheeduzzafar, Influence of corrosion and cracking on bond behaviour and strength of reinforced concrete members. ACI Structural Journal, 87 (2), 220-231, 1990.

[2] C. Andrade, C. Alonso, D. Garcia, J. Rodriguez, Remaining lifetime of reinforced concrete structures: Effect of corrosion on the mechanical properties of the steel. International conference on life prediction of corrodible structures, Cambridge, UK, 1991.

[3] J. Cairns, GA. Plizzari, Y. Du, DW. Law, C. Franzoni, Mechanical properties of corrosion-damaged reinforcement. ACI Materials Journal, 102(4), 2005.

[4] T. Hassan, S. Rizkalla, Investigation of bond in concrete structures strengthened with near surface mounted carbon fiber reinforced polymer strips. Journal of Composites of Constructions, 7(3):248-257, 2003.

[5] J. Barros, A. Fortes, Flexural strengthening of concrete beams with CFRP laminates bonded into slips. Cement and Concrete Composites, 27(4):471-480, 2005.

[6] A. Nour, B. Massicotte, E. Yildiz, V. Koval, Finite element modeling of concrete structures reinforced with internal and external fibre-reinforced polymers. Can. J. Civ. Eng., 34(3): 340-354, 2007.

[7] G. Camata, E. Spacone, R. Zarnic, Experimental and nonlinear finite element studies of RC beams strengthened with FRP plates. Composites Part B:Engineering, 38(2): 277-288, 2007.

[8] C. Coronado, M. Lopez, Sensitivity analysis of reinforced concrete beams strengthened with FRP laminates. Cement \& Concrete Composites, 28(1):102-114, 2006.

[9] F. Buyle-Bodin, E. David, E. Ragneau, Finite element modeling of flexural behaviour of externally bonded CFRP reinforced concrete structures, Engineering Structures; 24(11): 1423-1429, 2002.

[10] N. Kishi, G. Zhang, H. Mikami, Numerical cracking and debonding analysis of RC beams reinforced with FRP sheet. Journal of Composites for Construction, 9(6): 507-514, 2005. 
[11] J. Barros, R. Varma, J. Sena-Cruz, A. Azevedo, Near surface mounted CFRP strips for the flexural strengthening of RC columns-experimental and numerical study. Engineering structures, 30(12):3412-3425, 2008.

[12] H. Omran, R. El-Hacha, Nonlinear 3D finite element modeling of RC beams strengthened with prestressed NSM-CFRP strips. Construction and Building Materials, 74$85,2011$.

[13] A Hawileh, Nonlinear finite element modeling of RC beams strengthened with NSM FRP rods. Construction and Building Materials, 27(1):461-471, 2012.

[14] G. Camata, E. Spacone, R. Al-Mahaidi, V. Saouma, Analysis of test specimens for cohesive near-bond failure of fiber-reinforced polymer plated concrete. Journal of Composites for Construction, 8(6):528-538, 2004.

[15] H. Pham., R. Al-Mahaidi, V. Saouma, Modeling of CFRP-concrete bond using smeared and discrete cracks. Composites Structures, 75:145-150, 2006.

[16] M. Arduini, A.Tommaso, A. Nanni, Brittle failure in FRP plate and sheet bonded beams. ACI Structural Journal, 94(4):363-370, 1997.

[17] Z. Yang, J. Chen, D. Proverbs, Finite element modeling of concrete cover separation failure on FRP plated RC beams. Construction and Building Materials, 17(1):3-13, 2003.

[18] K. Neale, A. Godat, H. Abdel Baky, W. Elsayed, U. Ebead, Approaches for finite element simulations of FRP strengthened concrete beams and slabs. Architecture Civil Engineering Environment, 4:59-72, 2011.

[19] B. Almassri, F. Al Mahmoud, R. Francois, Behaviour of corroded reinforced concrete beams repaired with NSM CFRP rods, Experimental and Finite Element Study. Composites Part B: Engineering, 92:477-488, 2016.

[20] M. Rezazadeh, S. Cholostiakow, R. Kotynia, J. Barros, Exploring new NSM reinforcements for the flexural strengthening of RC beams: Experimental and numerical research. Composite Structures, 141:132-145, 2016.

[21] G. Manos, M. Theofanous, K. Katakalos, Numerical simulation of the shear behaviour of reinforced concrete rectangular beam specimens with or without FRP-strip shear reinforcement. Advances in Engineering Software, 67:47-56, 2014.

[22] ASTM G1-90 (2002), Standard Practice for Preparing, Cleaning and Evaluating Corrosion Test Specimens. ASTM International, West Conshohocken, Pa., 2002, 8pp

[23] SIMULIA Abaqus, Theory Manual (6.12). Providence, RI, USA: Dassault Systems; 2012.

[24] P. Kmiecik, M. Kaminski, Modeling of reinforced concrete structures and composite structures with concrete strength degradation taken into consideration, Archives of Civil and Mechanical Engineering, Wroclaw University of Technology. No 3, Poland, 2011.

[25] Eurocode 2: design of concrete structures. Part 1-1: general rules and rules for buildings. Brussels 2004.

[26] R. Seracino, M. Saifulnaz, D. Oehlers, Generic deonding resistance of EB and NSM pate-to-concrete joints, Journal of Composites for Construction, 11(1):62-70, 2007.

[27] J. Cruz, J. Barros, Modeling of bond between near surface mounted CFRP laminate strips and concrete, Computers and Structures, 82:1513-1521, 2004.

[28] A. Turon, C.Davila, P. Camanho, J. Costa, An engineering solution for mesh size effects in the simulation of delamination using cohesive zone models. Engineering Fracture Mechanics, 74(10):1665-1682, 2007. 